\title{
Rational Inattention, Long-run Consumption Risk, and Portfolio Choice*
}

\author{
Yulei $\mathrm{Luo}^{\dagger}$
}

August 23, 2008

\begin{abstract}
This paper explores how the introduction of rational inattention (RI) - that agents process information subject to finite channel capacity - affects optimal consumption and investment decisions in an otherwise standard intertemporal model of portfolio choice. We first explicitly derive optimal consumption and portfolio rules under RI and then show that introducing RI reduces the optimal share of savings invested in the risky asset because inattentive investors face greater long-run consumption risk. We also show that the investment horizon matters for portfolio allocation in the presence of RI, even if investment opportunities are constant and the utility function of investors is constant relative risk aversion. Second, after aggregating across investors, we show that introducing RI can better explain the observed joint dynamics of aggregate consumption and the asset return. Finally, we show that RI increases the implied equity premium because investors under RI face greater long-run consumption risk and thus require higher compensation in equilibrium.
\end{abstract}

JEL Classification Numbers: D81, E21, G11.

\footnotetext{
*An earlier version of this paper was circulated under the title: "Rational Inattention, Portfolio Choice, and the Equity Premium." I would like to thank Christopher Sims, Michael Haliassos, Winfried Koeniger, Jonathan Parker, Ricardo Reis, Raman Uppal, Wei Xiong, and Chi-wa Yuen, as well as seminar and conference participants at Princeton University, University of Warwick, University of Guelph, University of Hong Kong, European University Institute, and the SED meeting for helpful comments and suggestions.

${ }^{\dagger}$ School of Economics and Finance, University of Hong Kong, Hong Kong. E-mail: yluo@econ.hku.hk.
} 


\section{Introduction}

Optimal asset allocation is a classic problem in finance and macroeconomics. In a canonical two-asset intertemporal portfolio choice model in which investment opportunities are constant and the utility function is power, the optimal share of savings invested in the risky asset is proportional to the expected excess return and the reciprocal of the volatility of the return to the risky asset and the coefficient of relative risk aversion. However, it is independent of either the investment horizon or the time discount factor of investors. Hence, the long-term portfolio choice is the same as the myopic portfolio choice. Furthermore, given the observed mean and volatility of the return to the risky asset and plausible degree of risk aversion, the canonical model generates a counterfactually high stock market participation rate. ${ }^{1}$ Another important topic that is closely related to portfolio choice is asset pricing. According to the canonical consumption-based capital asset pricing theory (CCAPM), the expected excess return on any risky portfolio over the risk-free interest rate is determined by the covariance of the excess return with contemporaneous consumption growth and the coefficient of relative risk aversion. Given the observed low covariance between equity returns and contemporaneous consumption growth, the canonical CCAPM theory thus predicts that equities are not very risky. Consequently, to generate the observed high equity premium measured by the difference between the average real stock return and the average short-term real interest rate, the coefficient of relative risk aversion must be very high. Mehra and Prescott (1985) examined this issue in the Lucas-type asset pricing framework and were the first to call it "the equity premium puzzle". ${ }^{2}$

An implicit but key assumption in the standard rational expectations (RE) version of the intertemporal portfolio choice model is that investors have unlimited information-processing capacity and thus can observe the state variable(s) without error. Consequently, they can react instantaneously and completely to any innovations to equity returns. However, the assumption that ordinary agents can observe the relevant state without errors is too strong to be consistent with the reality because complete observation requires costless super computing and information processing ability that normal agents may not possess in the real world. ${ }^{3}$ In fact, ordinary

\footnotetext{
${ }^{1}$ In a country with a well-developed equity culture like the U.S., the direct ownership of publicly traded stocks was only $21.3 \%$ in the 2001 Survey of Consumer Finance (SCF).

${ }^{2}$ For the history of this puzzle, see Hansen and Singeton (1983), Mehra and Prescott (1985), Weil (1989), Hansen and Jagannathan (1991), and Cochrane and Hansen (1992). Kocherlakota (1996) and Campbell (2002) gave useful reviews on this topic.

${ }^{3}$ As shown in Shannon (1948), measuring a real-value stochastic process without error implies an infinite
} 
people face many competing demands for their information capacity every period, so the amount of capacity devoted to processing financial information could be much lower than their total capacity. Hence, it is reasonable to assume that ordinary people only have limited informationprocessing capacity. As a result, they cannot observe the state(s) perfectly and thus have to react to the innovations slowly and incompletely. Sims (2003) first introduced this type of information capacity constraints into economics and called it "rational inattention" (henceforth, RI). In Sims' RI framework, the entropy concept is imported from information theory to measure the uncertainty of a random variable. More precisely, entropy describes the uncertainty embodied in the probability density function of a random variable. Further, the reduction in the entropy can be used to measure information flow. If there is an input and an output in a channel, the capacity is the maximum amount of information that flows through the channel. For finite channel capacity, the reduction in entropy is bounded by the capacity. Sims also solved linearquadratic (LQ) optimization problems that arise when individuals only have finite capacity in processing information. He showed that the optimal reactions of individuals are slow with respect to fundamental shocks and quick to the endogenous noises, which simultaneously explains the observed behavior of inertia (slow reaction to fundamentals) and volatility (quick reaction to noises).

The main objective of this paper is to apply the RI idea in an intertemporal model of portfolio choice and examine how RI affects optimal consumption-savings and long-term asset allocation. Given the explicit solution of optimal consumption and portfolio rules, we examine how RI affects the equilibrium risk premium and the joint dynamics of aggregate consumption and asset returns. As the first contribution of this paper, we explicitly solve for optimal consumption and portfolio rules in an RI version of the intertemporal model of portfolio choice. Specifically, we show that consumption adjusts slowly to the innovation to the equity return and quickly to its own shock (the endogenous error). The intuition is simple: ordinary investors only devote finite information capacity to observing the state of the evolution of their financial wealth, and thus the state variable(s) cannot be perfectly observed. In other words, information about changes in the true state cannot be entirely incorporated into decision making instantaneously and completely, so investors have to take some time to digest new information.

Second, given the slow adjustment in consumption to the wealth shocks due to RI, the amount of information processing capacity. 
quantity of the risk of the risky portfolio should be determined by its ultimate (long-term) consumption risk instead of its contemporaneous risk. Parker (2003) and Parker and Jullard (2005) presented convincing empirical evidence to argue that the ultimate consumption risk is a better measure for the riskiness of the risky portfolio than the contemporaneous risk because in the data consumption takes many periods to adjust to the innovations to risky assets. Therefore, under RI, the ultimate consumption risk is greater than the contemporaneous risk and investors with finite capacity would choose to invest less in the risky asset. The intuition is that it is irrational for investors to invest a large fraction of their wealth in the risky asset if they cannot allocate enough channel capacity in monitoring their financial wealth, because the innovations to their financial wealth can generate large consumption risk in the long run if the capacity is low.

Third, given the solution of optimal asset allocation, we show that the long-term consumption risk and the demand for the risky asset depend both on the degree of RI and on the discount factor when the coefficient of relative risk aversion is close to 1. In this infinite horizon setting, the discount factor can be used to characterize the effective investment horizon; ${ }^{4}$ hence, the fact that the demand for the risky asset depends on the discount factor also means that the investment horizon matters for portfolio allocation. In addition, if we allow for a heterogenous degree of inattention in the model, RI could provide an alternative explanation for "the limited stock market participation" observed in the US data because investors with a very low degree of attention might face extremely large long-term consumption risk, which restricts their participation in the stock market.

Finally, after aggregating across all investors, we demonstrate that RI can help reconcile three observations in the US data: (1) the smooth process of aggregate consumption, (2) low contemporaneous correlation between aggregate consumption and the equity return, and (3) the high risk premium in equilibrium. It is also shown that holding the discount factor constant, increasing the degree of inattention is observationally equivalent to increasing the effective coefficient of relative risk aversion that matters for asset allocation. Hence, even if the true value of the coefficient of relative risk aversion is only around 1 , the effective coefficient would be higher than 1 if the investor is highly inattentive. In other words, RI can reconcile low estimates of risk aversion obtained from experimental evidence or introspection, with high estimated values

\footnotetext{
${ }^{4}$ That is, the lower the time discount factor, the shorter the investment horizon.
} 
of risk aversion based on asset pricing data.

Some recent papers incorporate explicit information processing constraints into a variety of theoretical models and explore how they affect individual decisions, optimal monetary policy, and equilibrium. For example, Moscarini (2004) derived optimal time-dependent adjustment rules from the information constraints in a continuous-time framework. Adam (2005) analyzed the effects of imperfect common knowledge on monetary policy. Peng (2004) explored the effects of information constraints on the equilibrium asset price dynamics and consumption behavior under the continuous-time CARA framework. Huang and Liu (2006) showed that inattention to important news may make investors overinvest or under-invest. ${ }^{5}$ Peng and Xiong (2005) discussed investors' attention and overconfidence. van Nieuwerburgh and Veldkamp (2006) studied information acquisition and portfolio under-diversification.

A number of papers have explored the implications of delayed adjustment for asset pricing and aggregate dynamics from another perspective. For example, Lynch (1996) examined the effects of infrequent decision-making for aggregate consumption and asset returns; Marshall and Parekh (1999) addressed how costs of adjustment help explain the asset return puzzles; Gabaix and Laibson (2001) followed their research line and showed that updating optimal decisions infrequently can better explain the equity premium puzzle in a continuous-time model. The main difference between the Gabaix and Laibson's $6 D$ model and our RI model is that in their model, investors adjust their consumption plans infrequently but completely once they choose to adjust, while investors with finite capacity adjust their plans frequently but incompletely in every period. Another important difference between these two models concerns the optimal asset allocation. Specifically, in the $6 D$ model, the optimal fraction of savings invested in the risky asset is assumed to be fixed at the standard Merton solution. On the other hand, the portfolio choice under RI reflects the larger long-term consumption risk caused by slow adjustments and thus the share invested in the risky asset is less than the Merton solution. It is worth noting that although both models can generate the observed smooth aggregate consumption as well as the joint behavior of aggregate consumption and the asset return, their aggregation mechanisms are distinct. Specifically, in the $6 D$ model, aggregation leads to aggregate consumption

\footnotetext{
${ }^{5}$ They used "rational inattention" to describe a situation in which information is updated completely but infrequently. This alternative formulation is more tractable but is different from Sims' RI idea - it permits agents to process infinite amounts of information when they choose to do so. However, the essence of RI proposed by Sims (2003) is that agents cannot use all available information because most of the time they are not paying that much attention to market signals and thus cannot digest all of the available information.
} 
smoothness because of the synchronization problem caused by infrequent adjustments across individual investors, whereas the RI model generates smooth consumption because the idiosyncratic noises due to finite idiosyncratic channel capacity are cancelled out after aggregating across all investors.

This paper is organized as follows. Section 2 solves a long-term portfolio choice model with RI and examines the implications of RI for optimal consumption and investment decisions. Section 3 examines how RI affects the joint dynamics of aggregate consumption and asset returns and the implied equity premium. Section 4 presents some suggestive empirical evidence. Section 5 concludes.

\section{An Intertemporal Portfolio Choice Model with Rational Inat- tention}

In this section, we first present and review a standard intertemporal portfolio choice model in the vein of Merton (1969), and then discuss how to incorporate RI into this otherwise standard model. Following the log-linear approximation method proposed by Campbell (1993), Viceira (2001), and Campbell and Viceira (2002), we explicitly solve an RI version of the portfolio choice model after considering the long-term consumption risk facing investors. A major advantage of the log-linearization approach is that we can approximate the original nonlinear problem by a log linear-quadratic (LQ) framework when the coefficient of relative risk aversion is close to 1 and thus can justify the optimality of Gaussian posterior uncertainty under RI. We finally discuss the implications of RI for optimal consumption and investment decisions. In the next section, we will examine how RI affects the joint dynamics of aggregate consumption and the asset return as well as the equity premium in equilibrium.

\subsection{Specification and Solution of the Standard RE Portfolio Choice Model}

It is helpful to present the standard portfolio choice model and then discuss how to introduce RI in this framework before setting up and solving the portfolio choice model with RI. Here we consider a simple intertemporal model of portfolio choice with a continuum of identical investors. ${ }^{6}$ We first assume that investors choose consumption and asset holdings to maximize

\footnotetext{
${ }^{6}$ The model is based on Campbell (1993), Viceira (2001), and Campbell and Viceira (2002), and is widely adopted in the macroeconomics and finance literature.
} 
the intertemporal time-separable utility, defined over consumption:

$$
\max _{\left\{C_{t}, \alpha_{t}\right\}_{t=0}^{\infty}} E_{0}\left[\sum_{t=0}^{\infty} \beta^{t} u\left(C_{t}\right)\right]
$$

where $u\left(C_{t}\right)=\frac{C_{t}^{1-\gamma}-1}{1-\gamma}$ is the power utility function, $C_{t}$ represents individual's consumption at time $t, \beta$ is the discount factor, and $\gamma$ is the coefficient of relative risk aversion. When $\gamma=1$, the utility function becomes logarithmic form, $\log C_{t}$.

For simplicity, we assume that the investment opportunity set is constant. There are two tradable financial assets in the model economy: Asset $e$ is risky, with one-period log (continuously compounded) return $r_{t+1}^{e}$, while the other asset $f$ is riskless, with constant log return given by $r^{f}$. We refer to asset $e$ as the market portfolio of equities, and asset $f$ as savings or checking accounts. Furthermore, we assume that $r_{t+1}^{e}$ has expected return $\mu$, where $\mu-r^{f}$ is the equity premium, and an unexpected component $u_{t+1}$ with $\operatorname{var}\left[u_{t+1}\right]=\omega^{2}$.

The intertemporal budget constraint for the investor is

$$
A_{t+1}=R_{t+1}^{p}\left(A_{t}-C_{t}\right)
$$

where $A_{t+1}$ is the individual's financial wealth which is defined as the value of financial assets carried over from period $t$ at the beginning of period $t+1, A_{t}-C_{t}$ is savings, and $R_{t+1}^{p}$ is the one-period gross return on savings given by

$$
R_{t+1}^{p}=\alpha_{t}\left(R_{t+1}^{e}-R^{f}\right)+R^{f}
$$

where $R_{t+1}^{e}=\exp \left(r_{t+1}^{e}\right), R^{f}=\exp \left(r^{f}\right)$, and $\alpha_{t}=\alpha$ is the proportion of savings invested in the risky asset. ${ }^{7}$ As shown in Campbell (1993), the following approximate expression for the log return on wealth holds:

$$
r_{t+1}^{p}=\alpha\left(r_{t+1}^{e}-r^{f}\right)+r^{f}+\frac{1}{2} \alpha(1-\alpha) \omega^{2}
$$

Given the above model specification, it is well known that this simple discrete-time model can not be solved analytically. ${ }^{8}$ We then follow the log-linearization method proposed in Campbell

\footnotetext{
${ }^{7}$ Given i.i.d. equity returns and power utility function, the share invested in equities, $\alpha_{t}$, is constant over time.

${ }^{8}$ Of course, it can be solved by using numerical methods adopted widely in the modern consumption and
} 
(1993), Viceira (2001), and Campbell and Viceira (2002) to approximately solve the model in closed-form. Specifically, the original intertemporal budget constraint, (2), can be written in log-linear form:

$$
\Delta a_{t+1}=(1-1 / \phi)\left(c_{t}-a_{t}\right)+\psi+r_{t+1}^{p}
$$

where the steady state $c-a=E\left[c_{t}-a_{t}\right], \phi=1-\exp (c-a), \psi=\log \phi-(1-1 / \phi) \log (1-\phi)$, and lowercase letters denote logs. The optimal consumption and portfolio rules for this standard intertemporal model are as follows: ${ }^{9}$

$$
\begin{aligned}
c_{t} & =b_{0}+a_{t}, \\
\alpha & =\frac{\mu-r^{f}+0.5 \omega^{2}}{\gamma \omega^{2}},
\end{aligned}
$$

where

$$
b_{0}=\log \left(1-\exp \left(\left(\frac{1}{\gamma}-1\right) E_{t}\left[r_{t+1}^{p}\right]+\frac{1}{\gamma} \log \beta+\frac{1}{2 \gamma}(1-\gamma)^{2} \operatorname{var}_{t}\left[r_{t+1}^{p}\right]\right)\right) .
$$

Hence, the optimal portfolio rule is independent of the consumption rule, and when $\gamma=1$, the consumption rule is also independent of the stochastic properties of financial assets. Furthermore, combining (5) with (6) gives the expression for the change in consumption: ${ }^{10}$

$$
\Delta c_{t+1}=\alpha u_{t+1}
$$

\subsection{Rational Inattention as a Consequence of Information-processing Con- straints}

The standard rational expectations (RE) models implicitly assume that individuals have unlimited information-processing ability and thus can incorporate all available information into economic decisions. However, in reality, ordinary consumers/investors have only finite capacity that they can use to process economic and financial information because they face many competing demands for their capacity; consequently, they cannot adjust their optimal plans instantaneously and completely. In this paper, we introduce rational inattention (RI) by assuming

portfolio choice literature.

${ }^{9}$ See the Appendix in Viceira (2001) for detailed derivations.

${ }^{10}$ Under RE, individual consumption growth and aggregate consumption growth have the same expression. 
that investors face information-processing constraints. As in Sims (2003), we use the concept of entropy from information theory to characterize the uncertainty of a random variable and then use the reduction in entropy to quantify information flow. With finite capacity $\kappa \in[0, \infty)$, the true state $a_{t+1}$ cannot be observed without errors and thus the information set at time $t+1, \mathcal{I}_{t+1}$, is generated by observing a noisy signal $a_{t+1}^{*}$ given by $a_{t+1}^{*}=a_{t+1}+\xi_{t+1}$, where $\xi_{t+1}$ is the endogenous idiosyncratic noise caused by finite capacity and independent of the fundamental shock. The investors under RI will choose a new signal $a_{t+1}^{*} \in \mathcal{I}_{t+1}=\left\{a_{1}^{*}, a_{2}^{*}, \cdots, a_{t+1}^{*}\right\}$ that reduces the uncertainty of the state variable $a_{t+1}$ as much as possible. Formally, this idea can be described by the following information constraint

$$
\mathcal{H}\left(a_{t+1} \mid \mathcal{I}_{t}\right)-\mathcal{H}\left(a_{t+1} \mid \mathcal{I}_{t+1}\right) \leq \kappa
$$

where $\kappa$ is the investor's information channel capacity, $\mathcal{H}\left(a_{t+1} \mid \mathcal{I}_{t}\right)$ denotes the entropy of the state prior to observing the new signal at $t+1$, and $\mathcal{H}\left(a_{t+1} \mid \mathcal{I}_{t+1}\right)$ is the entropy after observing the new signal. $\kappa$ imposes an upper bound on the amount of information - that is, the change in the entropy - that can be transmitted in any given period.

Following the literature, suppose that the ex ante $a_{t+1}$ is a Gaussian random variable. If the objective function is quadratic, minimizing the expected loss due to incomplete observations subject to $(10)$ is equivalent to minimizing the ex post variance of the state variable, $\operatorname{var}\left[a_{t+1} \mid \mathcal{I}_{t+1}\right]$, or the variance of the noise, $\operatorname{var}\left[\xi_{t+1}\right]$, subject to the same constraint (which means that the ex post entropy must lie above a certain threshold: $\left.\mathcal{H}\left(a_{t+1} \mid \mathcal{I}_{t+1}\right) \geq \mathcal{H}\left(a_{t+1} \mid \mathcal{I}_{t}\right)-\kappa\right)$. Shannon (1948) showed that for a given entropy, Gaussian distribution minimizes the variance of the variable. Thus, the idiosyncratic noise, $\xi_{t+1}$, should be Gaussian such that the posterior distribution at $t+1$ (after observing the noisy signal $a_{t+1}^{*}=a_{t+1}+\xi_{t+1}$ ) is also Gaussian; that is, $a_{t+1} \mid \mathcal{I}_{t+1} \sim N\left(\widehat{a}_{t+1}, \Sigma_{t+1}\right)$, where $\widehat{a}_{t+1}=E\left[a_{t+1} \mid \mathcal{I}_{t+1}\right]$ and $\Sigma_{t+1}=\operatorname{var}\left[a_{t+1} \mid \mathcal{I}_{t+1}\right]$ are the conditional mean and variance, respectively, and (10) is binding:

$$
\mathcal{H}\left(a_{t+1} \mid \mathcal{I}_{t}\right)-\mathcal{H}\left(a_{t+1} \mid \mathcal{I}_{t+1}\right)=\kappa
$$


Because both ex ante and ex post state variables are Gaussian, (11) reduces to ${ }^{11}$

$$
\frac{1}{2}\left(\log \Psi_{t}-\log \Sigma_{t+1}\right)=\kappa,
$$

where $\Sigma_{t+1}=\operatorname{var}\left[a_{t+1} \mid \mathcal{I}_{t+1}\right]$ and $\Psi_{t}=\operatorname{var}\left[a_{t+1} \mid \mathcal{I}_{t}\right]$ are the posterior and the prior variance of $a_{t+1}$. This means that given a finite capacity $\kappa$ per time unit, the optimizing investor would choose a signal that reduces the conditional variance by $\frac{1}{2}\left(\log \Psi_{t}-\log \Sigma_{t+1}\right)$. We will discuss how to determine the dynamics of the conditional mean $\widehat{a}_{t+1}$ as well as the conditional variance $\Sigma_{t+1}$ and the variance of the noise var $\left[\xi_{t+1}\right]$ in detail when we solve the intertemporal portfolio choice model with RI.

\subsection{Incorporating RI into the Standard Model}

As shown in Sims (2003, 2005), the linear-quadratic optimal problem can rationalize Gaussian posterior uncertainty as optimal, while the non-LQ setup easily generates optimal non-Gaussian posterior uncertainty. ${ }^{12}$ Given the specification of the above standard model, it is straightforward to show that when $\gamma$ is very close to 1 from above such that $(\gamma-1) c_{t}$ is close to 0 , the original power utility function can be approximated by a log-LQ function. ${ }^{13}$ Specifically, approximating the original utility function around $(\gamma-1) c_{t}=0$ gives:

$$
\frac{C_{t}^{1-\gamma}-1}{1-\gamma}=\frac{\left(\exp \left(c_{t}\right)\right)^{1-\gamma}-1}{1-\gamma} \simeq c_{t}+\frac{1}{2}(1-\gamma) c_{t}^{2}+\frac{1}{6}(1-\gamma)^{2} c_{t}^{3}
$$

where the third term, $\frac{1}{6}(1-\gamma)^{2} c_{t}^{3}$, measures prudence. Note that since the ratio of the third term to the second term in the above approximation, $\frac{1}{3}(\gamma-1) c_{t}$, is close to 0 when $(\gamma-1) c_{t}$ is close to 0 , the original power function can be approximated by a log-LQ function, $c_{t}+\frac{1}{2}(1-\gamma) c_{t}^{2}$. Hence, when $\gamma$ is close to 1 , solving the original non-LQ optimization problem is equivalent to maximizing the $\log$-LQ objective function $c_{t}+\frac{1}{2}(1-\gamma) c_{t}^{2}$ subject to the log-linearized budget constraint, (5).

We now discuss how to incorporate RI in this log-linearized model. First, we redefine $c_{t}$ as

\footnotetext{
${ }^{11}$ Here we use the fact that the entropy of a Gaussian random variable is equal to half of its logarithm variance plus some constant term.

${ }^{12}$ For example, Sims (2005) showed in a simple two-period saving problem that when the utility function is non-quadratic, the optimal ex post uncertainty follows non-Gaussian distribution.

${ }^{13}$ Calibrated macroeconomic models designed to match growth and business cycle facts typically require that the coefficient of relative risk aversion be close to 1 (slightly greater than 1) and the intertemporal elasticity of substitution also be close to 1 (slightly less than 1). For example, see Weil (1989).
} 
the new control variable and $a_{t}$ as the new state variable. Then, following Sims $(2003,2005)$ and Luo (2007), among others, we assume that the typical investor maximizes his lifetime utility subject to the budget constraint, (5), as well as the information-processing constraint that will be specified later. The dynamic optimization problem of the investor can be written as

$$
\widehat{v} \simeq \max _{\left\{c_{t}, \mathcal{D}_{t}\right\}} E_{0} \sum_{t=0}^{\infty} \beta^{t}\left[c_{t}+\frac{1}{2}(1-\gamma) c_{t}^{2}\right]
$$

subject to

$$
\begin{aligned}
\Delta a_{t+1} & =(1-1 / \phi)\left(c_{t}-a_{t}\right)+\psi+r_{t+1}^{p} \\
a_{t+1} \mid \mathcal{I}_{t+1} & \sim \mathcal{D}_{t+1}, \\
a_{t} \mid \mathcal{I}_{t} & \sim \mathcal{D}_{t}
\end{aligned}
$$

given $a_{0} \mid \mathcal{I}_{0} \sim N\left(\widehat{a}_{0}, \Sigma_{0}\right)$, and the requirement that the rate of information flow at $t+1$ implicit in the specification of the distributions, $\mathcal{D}_{t}$ and $\mathcal{D}_{t+1}$ be less than channel capacity, ${ }^{14}$ and $\mathcal{I}_{t}$ is the information available at time $t$. The expectation is formed under the assumption that $\left\{c_{t}\right\}_{t=0}^{\infty}$ are chosen under the information processing constraints.

In the presence of RI, individual investors cannot observe the state(s) perfectly because observing the state involves information transfer at a limited channel capacity $\kappa$, so they must choose the nature of the endogenous error optimally. For simplicity, here we assume that all individuals in the model economy have the same channel capacity; hence the average capacity in the economy is equal to individual capacity. ${ }^{15}$ In this case the perceived state variable is not the traditional state variable (e.g., the wealth level $a_{t}$ in this model), but the so-called information state: the distribution of the true state variable, $a_{t}$, conditional on the information set available at time $t, \mathcal{I}_{t}$.

As discussed Section 2.2, for the LQ specification, ex-post Gaussian uncertainty is optimal, that is,

$$
a_{t+1} \mid \mathcal{I}_{t+1} \sim N\left(\widehat{a}_{t+1}, \Sigma_{t+1}\right)
$$

where $\widehat{a}_{t+1}=E\left[a_{t+1} \mid \mathcal{I}_{t+1}\right]$ and $\Sigma_{t+1}=\operatorname{var}\left[a_{t+1} \mid \mathcal{I}_{t+1}\right]$ are the conditional mean and variance of

\footnotetext{
${ }^{14}$ As shown in Sims $(2003,2005)$, within the LQ framework, $\mathcal{D}_{t}$ and $\mathcal{D}_{t+1}$ follow normal distributions.

${ }^{15}$ Assuming that channel capacity follows some distribution complicates the problem when aggregating, but it does not change the main findings.
} 
$a_{t+1}$, respectively. The idiosyncratic error $\xi_{t+1}$ and the noisy signal $a_{t+1}^{*}=a_{t+1}+\xi_{t+1}$ are both chosen to be Gaussian such that

$$
\frac{1}{2}\left(\log \Psi_{t}-\log \Sigma_{t+1}\right)=\kappa,
$$

where $\Sigma_{t+1}=\operatorname{var}_{t+1}\left[a_{t+1}\right]$ and $\Psi_{t}=\operatorname{var}_{t}\left[a_{t+1}\right]$ are the posterior and prior variance, respectively. This means that given a finite capacity $\kappa$ per time unit, the optimizing consumer would choose a signal that reduces the conditional variance by $\frac{1}{2}\left(\log \Psi_{t}-\log \Sigma_{t+1}\right) .{ }^{16}$ Note that in the univariate state case this information constraint completes the characterization of the optimization problem.

Given the budget constraint, (5), we have

$$
\begin{aligned}
E_{t}\left[a_{t+1}\right] & =E_{t}\left[r_{t+1}^{p}\right]+\psi+\widehat{a}_{t}, \\
\operatorname{var}_{t}\left[a_{t+1}\right] & =\operatorname{var}_{t}\left[r_{t+1}^{p}\right]+(1 / \phi)^{2} \Sigma_{t}
\end{aligned}
$$

Substituting (16) into (15) then gives

$$
\kappa=\frac{1}{2}\left[\log \left(\operatorname{var}_{t}\left[r_{t+1}^{p}\right]+(1 / \phi)^{2} \Sigma_{t}\right)-\log \Sigma_{t+1}\right]
$$

which has a steady state $\Sigma=\frac{\operatorname{var}_{t}\left[r_{t+1}^{p}\right]}{\exp (2 \kappa)-(1 / \phi)^{2}}$, where $\operatorname{var}_{t}\left[r_{t+1}^{p}\right]=\alpha^{2} \omega^{2}$.

We can now apply the separation principle in this log-LQ model to obtain the following modified consumption function by replacing $a_{t}$ with $\widehat{a}_{t}$ in $(6):{ }^{17}$

$$
c_{t}=\log (1-\phi)+\widehat{a}_{t}
$$

and the perceived state $\widehat{a}_{t}$ is characterized by the following Kalman filter equation:

$$
\widehat{a}_{t+1}=(1-\theta)\left[(1-1 / \phi) c_{t}+(1 / \phi) \widehat{a}_{t}-\log \phi+\psi\right]+\theta a_{t+1}^{*}
$$

\footnotetext{
${ }^{16}$ Note that given $\Sigma_{t}$, choosing $\Sigma_{t+1}$ is equivalent with choosing the noise var $\left[\xi_{t}\right]$ since the usual updating formula for the variance of a Gaussian distribution is

$$
\Sigma_{t+1}=\Psi_{t}-\Psi_{t}\left(\Psi_{t}+\operatorname{var}\left[\xi_{t}\right]\right)^{-1} \Psi_{t}
$$

where $\Psi_{t}$ is a function of $\Sigma_{t}$.

${ }^{17}$ Note that $\phi$ is independent of the degree of attention, $\kappa$, because $\phi$ approaches to $\beta$ as $\gamma$ converges to 1 .
} 
Combining them gives the evolution of $\widehat{a}_{t}$ :

$$
\widehat{a}_{t+1}=(1-\theta) \widehat{a}_{t}+\theta a_{t+1}^{*}
$$

where $\theta=1-\frac{1}{\exp (2 \kappa)}$ is the optimal weight on observation, $a_{t+1}^{*}=a_{t+1}+\xi_{t+1}$ is the observed signal, and $\xi_{t+1}$ are the i.i.d. noise with $\operatorname{var}\left[\xi_{t+1}\right]=\Sigma / \theta$.

Hence, combining equations (5), (17), with (19) gives the expression for individual consumption growth: ${ }^{18}$

$$
\Delta c_{t+1}=\theta\left[\frac{\alpha u_{t+1}}{1-((1-\theta) / \phi) \cdot L}+\left(\xi_{t+1}-\frac{(\theta / \phi) \xi_{t}}{1-((1-\theta) / \phi) \cdot L}\right)\right]
$$

where $L$ is the lag operator.

Note that none of the above expressions for consumption, the perceived state, and the change in consumption are the final solutions because the optimal fraction of savings invested in stock market, $\alpha$, is still undetermined. The reason is that we need to use the Euler equation to determine the optimal allocation in risky assets. However, as we will discuss in the next subsection, the standard Euler equation does not hold in the RI model because consumption under information-processing constraints adjusts gradually and incompletely. Therefore, we will discuss how to determine the optimal portfolio allocation after considering the long-term Euler equation and the ultimate consumption risk.

\subsection{Long-term Consumption Risk and the Demand for the Risky Asset}

Parker (2001; 2003) and Parker and Julliard (2005) provided convincing empirical evidence to argue that the long-term risk is a better measure of the true risk of the stock market if consumption reacts with a delay to changes in wealth because the contemporaneous covariance of consumption and wealth understates the risk of equity. ${ }^{19}$ Hansen, Heaton, and Li (2006) found a small Long-run risk component in the consumption data. Hence, we need to use the long-term consumption risk to measure the risk of the equity in the RI model because the RI model predicts that consumption reacts gradually and with delay to the innovations to the

\footnotetext{
${ }^{18}$ Note that this $\mathrm{MA}(\infty)$ expression requires that $(1-\theta) / \phi<1$, which is equivalent to $\kappa>\frac{1}{2} \log (1 / \phi)$.

${ }^{19}$ Bansal and Yaron (2004) also documented that consumption and dividend growth rates contain a long-run component. An adverse change in the long-run component lowers asset prices and thus makes holding equity very risky for investors.
} 
equity.

In this subsection, we first define the long-term consumption risk in the RI model and then derive the optimal portfolio rule. Substituting the optimal portfolio rule into the consumption function and the changes in consumption gives us a complete solution to this simple optimal consumption and portfolio choice model with RI. Following Parker's work, we define the longterm consumption risk as the covariance of asset returns and consumption growth over the period of the return and many following periods. Because the RI model predicts that consumption reacts to the innovations to asset returns gradually and incompletely, it can rationalize the conclusion in Parker's papers that consumption risk should be long term instead of contemporaneous. ${ }^{20}$

Given the above analytical solution for consumption growth, it is straightforward to calculate the ultimate consumption risk under RI. Specifically, when agents behave optimally but only have finite channel capacity, we have the following equality for the risky asset $e$ and the risk-free asset $f:{ }^{21}$

$$
E_{t}\left[R_{t+1}^{e} C_{t+1+S}^{-\gamma}\right]=E_{t}\left[R^{f} C_{t+1+S}^{-\gamma}\right]
$$

which can be transformed to the following stationary form:

$$
E_{t}\left[R_{t+1}^{e}\left(C_{t+1+S} / C_{t}\right)^{-\gamma}\right]=E_{t}\left[R^{f}\left(C_{t+1+S} / C_{t}\right)^{-\gamma}\right]
$$

where $S$ is the number of periods in the future. ${ }^{22}$ The standard equality, $E_{t}\left[R_{t+1}^{e} C_{t+1}^{-\gamma}\right]=$ $E_{t}\left[R^{f} C_{t+1}^{-\gamma}\right]$, does not hold here because consumption reacts slowly with respect to the innovations to equity returns and thus cannot finish adjusting immediately and completely.

Log-linearizing equation (21) yields

$$
E_{t}\left[r_{t+1}^{e}\right]-r^{f}+\frac{1}{2} \omega^{2}=\gamma \operatorname{covar}_{t}\left[c_{t+1+S}-c_{t}, r_{t+1}^{e}\right]
$$

\footnotetext{
${ }^{20}$ Note that under RE, the contemporaneous consumption risk is the same as the ultimate consumption risk because consumption adjusts to wealth shocks instantly and completely.

${ }^{21}$ The equality can be obtained by using $S+1$ period consumption growth to price a multiperiod return formed by investing in equity for one period and then transforming to the risk-free asset for the next $S$ periods. Hence, the following multiperiod moment condition holds

$$
C_{t}^{-\gamma}=E_{t}\left[\beta^{S+1} C_{t+S+1}^{-\gamma} R_{t+1}^{e}\left(R^{f}\right)^{S}\right] .
$$

${ }^{22}$ This measure has some appealing features; see Parker (2003) and Parker and Jullard (2005) for detailed discussions.
} 
which means that the expected asset return can be written as:

$$
E_{t}\left[r_{t+1}^{e}\right]-r^{f}+\frac{1}{2} \omega^{2}=\gamma\left(\sum_{j=0}^{S} \operatorname{covar}_{t}\left[\Delta c_{t+j+1}, r_{t+1}^{e}\right]\right)
$$

where $c_{t+1+S}-c_{t}=\sum_{j=0}^{S} \Delta c_{t+1+j}$ and $\Delta c_{t+1+j}=\theta\left[\left(\frac{\alpha u_{t+1+j}}{1-((1-\theta) / \phi) \cdot L}\right)+\left(\xi_{t+1+j}-\frac{(\theta / \phi) \xi_{t+j}}{1-((1-\theta) / \phi) \cdot L}\right)\right]$. Specifically, the long-run impact of the innovation in the equity return on consumption growth can be rewritten as

$$
\lim _{S \rightarrow \infty}\left(\sum_{j=0}^{S} \operatorname{covar}_{t}\left[\Delta c_{t+1+j}, r_{t+1}^{e}\right]\right)=\varsigma \alpha \omega^{2}
$$

where $\varsigma$ is the ultimate consumption risk:

$$
\varsigma=\frac{\theta}{1-(1-\theta) / \phi}
$$

Because consumption adjusts gradually to the shocks to asset returns in the presence of RI, this ultimate consumption risk should be a better measure of the riskiness of the risky asset than the contemporaneous risk. Figure 1 illustrates the relationship between the ultimate risk $\varsigma$ and channel capacity $\kappa$. It clearly shows that the ultimate consumption risk decreases with channel capacity; that is, the more attention of the investor devoted to monitoring the evolution of his financial wealth, the less the ultimate consumption risk of the risky asset held by him.

Combining equations (23), (24), with (17) gives us optimal consumption and portfolio rules under RI. The following proposition gives a complete characterization of the model's solution:

Proposition 1 Given finite channel capacity $\kappa$, the optimal share invested in the equity is

$$
\alpha^{*}=\frac{1}{\varsigma} \frac{\mu-r^{f}+0.5 \omega^{2}}{\gamma \omega^{2}}
$$

where $\frac{1}{\varsigma}=\frac{1-(1-\theta) / \phi}{\theta}<1$. Furthermore, the consumption function is

$$
c_{t}^{*}=\log (1-\phi)+\widehat{a}_{t},
$$

the actual state variable evolves according to

$$
a_{t+1}=(1 / \phi) a_{t}+(1-1 / \phi) c_{t}^{*}+\psi+\left[\alpha^{*}\left(r_{t+1}^{e}-r^{f}\right)+r^{f}+\frac{1}{2} \alpha^{*}\left(1-\alpha^{*}\right) \omega^{2}\right]
$$


and the estimated state $\widehat{a}_{t}$ is characterized by the following Kalman filtering equation

$$
\widehat{a}_{t+1}=(1-\theta) \widehat{a}_{t}+\theta\left(a_{t+1}+\xi_{t+1}\right)
$$

where $\phi=1-\exp (c-a),{ }^{23} \psi=\log \phi-(1-1 / \phi) \log (1-\phi), \theta=1-\frac{1}{\exp (2 \kappa)}$ is the optimal weight on observation, $\xi_{t}$ are the i.i.d. idiosyncratic noise with $\omega_{\xi}^{2}=\operatorname{var}\left[\xi_{t+1}\right]=\Sigma / \theta$, and $\Sigma=\frac{\alpha^{* 2} \omega^{2}}{\exp (2 \kappa)-(1 / \phi)^{2}}$ is the steady state conditional variance. Finally, the change in individual consumption is

$$
\Delta c_{t+1}^{*}=\theta\left[\frac{\alpha^{*} u_{t+1}}{1-((1-\theta) / \phi) \cdot L}+\left(\xi_{t+1}-\frac{(\theta / \phi) \xi_{t}}{1-((1-\theta) / \phi) \cdot L}\right)\right]
$$

Proof. The proof is straightforward.

It is clear from this proposition that optimal consumption and portfolio rules are interdependent each other in the presence RI. Expression (25) shows that although the optimal fraction of savings invested in the risky asset is proportional to the risk premium $\left(\mu-r^{f}+0.5 \omega^{2}\right)$ and the reciprocal of both the coefficient of relative risk aversion $(\gamma)$ and the variance of the unexpected component in the risky asset $\left(\omega^{2}\right)$ as predicted by the standard Merton solution, it also depends on the long-term consumption risk measured by $\varsigma$. Note that (25) can be rewritten as

$$
\alpha^{*}=\frac{\mu-r^{f}+0.5 \omega^{2}}{\widetilde{\gamma} \omega^{2}},
$$

where the effective coefficient of relative risk aversion is $\widetilde{\gamma}=\gamma \varsigma>\gamma$. Hence, even if the true $\gamma$ is close to 1 as assumed at the beginning of this section, the effective risk aversion that matters for the optimal asset allocation is $\varsigma$ which could be much greater than 1 if the capacity is low. Therefore, both the degree of attention $(\theta)$ and the discount factor $(\beta)$ amount to an increase in the effective coefficient of relative risk aversion. Holding $\beta$ constant, the larger the degree of attention, the less the ultimate consumption risk. As a result, investors with low attention will choose to invest less in the risky asset. For example, with RI, a $1 \%$ percent negative shock in investors' financial wealth would affect their consumption more than that predicted by the standard RE model. Therefore, investors with finite capacity are less willing to invest in the risky asset. It is also worth noting that when the information capacity becomes infinitely large

\footnotetext{
${ }^{23} c-a=E\left[c_{t}-a_{t}\right]$ is the steady state value.
} 
(i.e., $\kappa=\infty$ and $\theta=1$ ), the RI model reduces to the standard RE model in which consumption reacts instantaneously and completely to the innovations and the optimal share in the risky asset is the same as the myopic solution.

Equations (26) and (29) show that individual consumption under RI reacts not only to fun-

damental shocks $\left(u_{t+1}\right)$ but also to its own endogenous noises $\left(\xi_{t+1}\right)$ induced by finite capacity. The endogenous noise can be regarded as a type of "consumption shock" or "demand shock". In the intertemporal consumption literature, some ad hoc transitory consumption shocks are modeled to make the model fit the data better. Under RI, the idiosyncratic noise due to RI could endogenize the exogenous ad hoc transitory consumption that lacks economic interpretations. Furthermore, equation (29) also makes it clear that consumption growth adjusts slowly and incompletely to the innovations to asset returns and reacts quickly to the idiosyncratic noises.

\subsection{Some Implications for Long-term Investment}

\subsubsection{Investment Horizon Does Matter}

In the standard RE portfolio choice model, the investment horizon is irrelevant for investors who have power utility functions, have only financial wealth and who face constant investment opportunities. By contrast, it is apparent from proposition 1 that with RI the investment horizon does matter for optimal asset allocations because it affects the long-term consumption risk. As argued in Campbell and Viceira (2002), we may vary the effective investment horizon by varying the discount factor $(\beta)$ that determines the relative weights investors put on the near future versus the distant future. The investors with large $\beta$ would place a relatively high weight on the distant future, while those with small $\beta$ place more weight on the near future. Note that if $\gamma$ is set to be close to $1, \phi \simeq \beta$. Hence, (25) clearly shows that the higher the value of $\beta$ (the longer the investment horizon), the more faction of financial wealth would be invested in the risky asset. Figure 2 illustrates how the investment horizon affects optimal asset allocation. The intuition is that those inattentive investors with larger $\beta$ face smaller long-term consumption risk; consequently they choose to invest more wealth in the risky asset.

Furthermore, this prediction can also be used to explain the investment behavior of the young and old. Financial advisors typically recommend that people shift investments away from the risky asset to the risk-free asset as they age. Some theoretical models have been proposed to evaluate this justification; for example, Jagannathan and Kocherlakota (1996), Viceira (2001), 
and Campbell and Viceira (2002). In the existing literature, the investment horizon and age are generally closely related. In other words, the old have low effective time discount factor because they face high death probability in every period. Hence, RI might provide an economic reasoning for this popular advice, and we can address the model's predictions for the behavior of the young and old by varying the value of $\beta$. Specifically, the old people with high $\beta$ face large ultimate consumption risk due to slow adjustment; consequently, it would be better for them to invest less in the stock market.

\subsubsection{Implications for Limited Stock Market Participation}

In the benchmark model, we assumed that every investor has the same level of channel capacity. However, in reality, investors have different levels of channel capacity in observing and processing information. Hence, in the heterogeneous-attention case, investors have different demands for the risky asset even if they have the same preference and face the common shock to the asset return. Based on (25), it is straightforward to show that "limited stock market participation" can arise endogenously in the RI model. ${ }^{24}$ The intuition is that the demand for the equity decreases with the degree of attention $(\theta)$. Therefore, the investor whose degree of attention is equal to or lower than the critical value $1-\phi,{ }^{25}$ will choose not to participate in the stock market because he faces extremely high ultimate consumption risk. Note that because our model abstracts from transaction costs, taxes, and short-sale constraints, among others, it may be very likely that those investors with low capacity (but still greater than the critical value) would also choose not to participate in the stock market if there are transaction costs. We do not explore this issue here and leave it for future research. Hence, the model composed of investors with different degrees of RI can generate "limited stock market participation" endogenously. Those investors who know that they cannot devote enough capacity to processing information about the evolution of their financial wealth choose not to invest in stock market because they face larger consumption risk.

\footnotetext{
${ }^{24}$ Although there is an upward trend in stock market participation in the PSID, the participation rate in the stock market including both direct and indirect investment is still less than 50\%. See Vissing-Jørgensen (2002) for a detailed discussion about limited asset market participation.

${ }^{25}$ Note that it is equivalent to say that $\kappa$ is equal or lower than $\frac{1}{2} \log (1 / \phi)$.
} 


\section{Implications for Aggregate Dynamics and Asset Returns}

\subsection{The Joint Dynamics of Aggregate Consumption and the Equity Return}

In this subsection, we provide a complete characterization of the joint dynamics of aggregate consumption and the asset return under RI. Specifically, we analyze several important properties of the joint behavior of financial markets and the real economy: the smoothness of consumption growth, low contemporaneous covariance between consumption growth and asset returns, positive autocorrelation of consumption growth, and non-zero covariance of consumption growth and lagged equity returns.

The endogenous noise due to finite capacity, $\xi_{t}$, is idiosyncratic because it arises from individuals' own internal information processing channels. Consequently, it can be cancelled out after aggregating across all investors. ${ }^{26}$ Given that the explicit expression of individual consumption, (29), is in exact aggregation form, aggregating individual consumption growth across all investors yields an expression for the change in aggregate consumption. ${ }^{27}$ Denoting aggregate consumption under RI as $c_{t},{ }^{28}$ the following proposition summarizes the implications of RI for the joint dynamics of aggregate consumption and the asset return:

Proposition 2 Aggregate consumption growth under RI can be written as

$$
\Delta c_{t+1}^{*}=\theta \frac{\alpha^{*} u_{t+1}}{1-((1-\theta) / \phi) \cdot L},
$$

where $\theta$ is the average degree of inattention in the model economy and $\alpha^{*}$ is the average optimal share invested in the risky asset and is given by (25). This dynamic equation implies that (1) the covariance between aggregate consumption growth and the asset return is

$$
\operatorname{covar}\left[\Delta c_{t+1}^{*}, r_{t+1}^{e}\right]=\theta \alpha^{*} \omega^{2}
$$

\footnotetext{
${ }^{26}$ Note that as discussed in Sims (2003), there might have been some aggregate component in the noise terms left after aggregating. If this is the case, we can see below that this additional term would affect the smoothness of aggregate consumption, but have no impact on the covariance between consumption growth and equity returns. The reason is that the endogenous noises and the innovations to equity returns are uncorrelated.

${ }^{27}$ For simplicity, we assume that individuals have identical channel capacity, $\theta$. Allowing for heterogeneity in $\theta$ would not affect the main results.

${ }^{28}$ Since we focus on aggregate behavior and to avoid the notation confusion, in the following equation, we still use $c$ to represent aggregate consumption.
} 
(2) the standard deviation of consumption growth is

$$
\operatorname{sd}\left[\Delta c_{t+1}^{*}\right]=\lambda \omega
$$

where the excess smoothness ratio $\lambda=\theta \alpha^{*} / \sqrt{1-((1-\theta) / \phi)^{2}}$, (3) the correlation between consumption growth and equity return is then

$$
\operatorname{corr}\left[\Delta c_{t+1}^{*}, r_{t+1}^{e}\right]=\sqrt{1-((1-\theta) / \phi)^{2}}
$$

(4) the autocorreltion of consumption growth is then

$$
\rho_{\Delta c(j)}=\operatorname{corr}\left[\Delta c_{t}^{*}, \Delta c_{t+j}^{*}\right]=\left[1-((1-\theta) / \phi)^{2}\right]((1-\theta) / \phi)^{j}
$$

where $j \geq 1$, and 5) the covariance between consumption growth and lagged equity returns is

$$
\operatorname{covar}\left[\Delta c_{t+1}^{*}, r_{t+1-j}^{e}\right]=\theta \alpha^{*}((1-\theta) / \phi)^{j} \omega^{2}
$$

where $j \geq 1$.

Proof. Using (31), it is straightforward to obtain the above results.

Expression (31) means that aggregate consumption adjusts gradually to the shock to the asset return, and thus the contemporaneous covariance between consumption growth and asset returns becomes $\theta \alpha^{*} \omega^{2}$ rather than $\alpha \omega^{2}{ }^{29}$ that is, the measured contemporaneous covariance between consumption growth and risky returns will be lowered by a factor $1-(1-\theta) / \phi$ in the presence of RI. The standard RE model predicts that this contemporaneous covariance is around $1.23 \cdot 10^{-3}$ at the quarterly frequency, which is well above its US empirical counterpart which is around $0.08 \cdot 10^{-3}$. When $\theta=30 \%$ or $\kappa=0.26$ bits (that is, approximately $30 \%$ of the uncertainty is removed upon receiving a new signal about financial wealth per quarter.) and $\beta=0.98$, the theoretical covariance value becomes $0.35 \cdot 10^{-3}$, which is much closer to the empirical value. It is worth noting that 1 bit of information transmitted is a very low number and is well below the total information-processing ability of human beings. However, it is not implausible for ordinary investors/consumers because they also face many other competing demands on

\footnotetext{
${ }^{29}$ Note that as given in $(7), \alpha=\frac{\mu-r^{f}+0.5 \omega^{2}}{\gamma \omega^{2}}$ is the optimal share invested in the stock market in the model without RI.
} 
capacity. Furthermore, low channel capacity devoted to processing available information can be rationalized because the welfare improvement from increasing capacity is tiny. ${ }^{30}$

Expression (33) means that RI can also reduce the standard deviation of aggregate consumption growth since the excess smoothness ratio $\lambda$ is less than $\alpha$, the excess smoothness ratio implied by the standard RE model. Figure 3 shows the relationship between the smoothness of consumption growth and channel capacity. It is clear from this figure that the smoothness of consumption growth increases with the degree of inattention. In the quarterly US data, the standard deviation of consumption growth is around $0.54 \cdot 10^{-2}$, which is well below $1.64 \cdot 10^{-2}$, the value predicted by the standard RE model. However, in the RI model with $\theta=30 \%$, the theoretical value of $\operatorname{sd}\left[\Delta c_{t+1}\right]$ becomes $0.5 \cdot 10^{-2}$, which is also close to the empirical one. Conversely, if given the volatility of consumption growth, (33) implies that RI has a potential to explain the equity volatility puzzle because $\lambda=[1-(1-\theta) / \phi] / \sqrt{1-((1-\theta) / \phi)^{2}}<1$; that is, the same volatility of consumption growth implies higher volatility of the equity in the presence of RI. ${ }^{31}$

Expression (35) shows that the autocorrelation of aggregate consumption growth is greater than $0 .{ }^{32}$ This finding is roughly consistent with some empirical evidence that the autocorrelation is significant up to the third quarter, which means that consumption growth is definitely not iid. ${ }^{33}$

Expression (36) shows that the covariance between consumption growth and lagged equity returns is greater than zero; that is, lagged equity returns can be used to predict future consumption growth. Further, the impacts of lagged returns on future consumption growth decrease at the rate $(1-\theta) / \phi$. It is obvious that in the absence of RI, lagged returns have no impact on consumption growth. In the next section, we will present existing empirical evidence that consumers may not have enough knowledge about their financial wealth and lagged returns to predict future consumption growth.

From the above proposition, it is obvious that given the empirical evidence, we can use

\footnotetext{
${ }^{30}$ Luo (2008) showed that the welfare losses due to information-processing constraints are very tiny within the linear-quadratic framework.

${ }^{31}$ See Campbell $(1999,2003)$ for a detailed discussion for this puzzle.

${ }^{32}$ Note that the standard RE model predicts that the autocorrelation of consumption growth is 0 , that is, consumption growth is iid.

${ }^{33}$ For example, Piazzesi (2001) reports the autocorrelation of consumption growth at different lags together with $95 \%$ confidence bounds and found that they are significant in the first several quarters. See Section 1.2 in her paper for a detailed description of the estimation.
} 
(34) or (35) to calibrate the average inattention in the economy governed by the structural parameter, $\theta$ or $\kappa$. For example, given that the observed contemporaneous correlation between aggregate consumption growth and asset returns is around 0.34 in the US quarterly data, ${ }^{34}$ one can calibrate the value of $\theta$ by setting $\sqrt{1-((1-\theta) / \phi)^{2}}=0.23$ and using the fact that $\phi \simeq \beta$. After choosing $\beta=0.98$, we have a calibrated $\theta$ equal to $10 \%$, that is, $\kappa=0.07$ bits, which means that to match the observed correlation between consumption growth and equity returns, the average degree of RI in the economy would be quite low. Further, using the expression for the autocorrelation $\rho_{\Delta c}(j)=\left[1-((1-\theta) / \phi)^{2}\right]((1-\theta) / \phi)^{j}$ where $j \geq 1$ and the empirical counterparts estimated from the US data, we may also calibrate $\kappa$. Piazzesi (2001) adopted the maximum likelihood method to estimate the US log aggregate consumption growth composed of an $A R(3)$ process combined with a Garch $(1,1)$ process and found that $\rho_{\Delta c}(1)=0.31$ with T-statistics $4.01 .^{35}$ Hence, setting $\rho_{\Delta c}(1)=0.31$ yields $\theta=27 \%$; that is, $\kappa=0.22$ bits, which also implies a low average level of inattention. Note that here we did not use confidence bounds based on standard errors. Hence, we cannot determine what value of $\kappa$ can satisfy all observed evidence exactly. However, it is obvious that a low value of $\kappa$ can roughly capture some main properties of the US data about consumption growth and asset returns: the standard deviation of aggregate consumption, the correlation between consumption growth and asset returns, and the autocorrelation of consumption growth. There are some existing estimation and calibration results in the literature. For example, Adam (2005) obtained an estimate of $\theta=40 \%$ in explaining the monetary policy reactions to both supply and demand shocks. In addition, Luo and Young (2008) found that setting $\theta=57 \%$ allows a otherwise standard RBC model to match the post-war U.S. consumption/output volatility.

\subsection{The Implications for the Equity Premium}

In the benchmark model, because every investor is assumed to have the same degree of RI, the following pricing equation linking aggregate consumption growth and the equity premium holds when $\gamma \simeq 1$ :

$$
\mu-r^{f}+0.5 \omega^{2}=\varsigma \alpha^{*} \omega^{2}
$$

\footnotetext{
${ }^{34}$ Campbell (2002) reports the correlations for different horizons in the quarterly data.

${ }^{35}$ For detailed estimation results, see table 1 in Piazzesi (2001).
} 
Suppose, as in the consumption-based CAPM literature, that the risk-free asset is an inside bond, so that in equilibrium the net supply of the risk free asset is 0 and then the share of the risky asset in financial wealth $\left(\alpha^{*}\right)$ is $100 \%$. Accordingly, (37) becomes

$$
\mu-r^{f}+0.5 \omega^{2}=\varsigma \omega^{2}
$$

Hence, RI implies higher equity premium because the ultimate consumption risk $\varsigma=\frac{\theta}{1-(1-\theta) / \phi}>$ $1 .^{36}$ The intuition behind this result is that investors facing higher ultimate consumption risk caused by finite capacity choose to invest less in the stock market and thus require higher risk compensation in equilibrium.

For illustrative purposes, we consider the following question: What will an economist equipped with the aggregate consumption-based CAPM model find if he observes data from the RI economy, but thinks he is observing data from the standard model? This question can be answered after observing that

$$
\widetilde{\gamma}=\frac{\mu-r^{f}+\frac{1}{2} \omega^{2}}{\operatorname{covar}\left[c_{t+1}-c_{t}, r_{t+1}^{e}\right]}=\frac{\mu-r^{f}+0.5 \omega^{2}}{\theta \alpha^{*} \omega^{2}}>\gamma \simeq 1
$$

where $\widetilde{\gamma}$ is the estimated coefficient of relative risk aversion and $\gamma$ is the true value that is close to 1 . The intuition is quite simple. The RI model can generate a very low value of $\operatorname{covar}\left[c_{t+1}-c_{t}, r_{t+1}^{e}\right]$ and a high equity premium simultaneously because the equity premium is determined by the long-term consumption risk, $\lim _{S \rightarrow \infty} \operatorname{covar}\left[c_{t+1+S}-c_{t}, r_{t+1}^{e}\right]$. In other words, the estimate of the coefficient of relative risk aversion is biased upward by a factor measured by the long-term consumption risk. For example, if the true $\gamma$ is 1 and $1-(1-\theta) / \phi=0.2$, the economist will find that the estimated value $\widetilde{\gamma}$ will be 5 . Hence, the estimated high coefficient in the asset pricing literature might arise from a low degree of the average attention in the economy instead of risk aversion itself. This result can reconcile two sets of empirical evidence: (1) relatively low values of risk aversion in introspection and experimental evidence and (2) high values of 'risk aversion' inferred from aggregate consumption and asset prices data.

\footnotetext{
${ }^{36}$ By contrast, without RI the pricing equation implies that in equilibrium $(\alpha=1)$ the equity premium is lower because $\mu-r^{f}+0.5 \omega^{2}=\omega^{2}$.
} 


\section{Review of Related Empirical Evidence}

Existing survey evidence supports that: (1) a significant fraction of investors do not have enough knowledge about the evolution of their financial wealth and consequently cannot adjust their consumption fully in response to the innovations to the returns, and (2) the innovations to their financial assets can be used to predict their future change in consumption. For example, Ameriks and Zeldes (2006) used pooled cross-sectional data from Surveys of Consumer Finance (SCF) to examine the dynamics of household portfolio shares. They found some important features of household portfolio behavior; for example, significant non-stockownership, and wide-ranging heterogeneity in asset allocation. As we discussed in Section 2, the optimal portfolio solution under RI, (25), can provide a partial explanation for these features because some investors with low attention face large ultimate consumption risk and thus choose not to invest in the stock market. Further, even if all investors have the same level of risk aversion, they may still choose different investment strategies due to the possible heterogeneity in inattention. In other words, RI introduces another type of heterogeneity.

Dynan and Maki (2001) analyzed the responses to the Consumer Expenditure Survey (CEX) from 1996 1. to 1999 1. and found that around one-third of stockholders reported no change in the value of their assets whereas the US stock markets rose over $15 \%$ per year during this sample period. ${ }^{37}$ In the same paper, they also reported that for stockholders with more than $\$ 10,000$ in securities, a $1 \%$ increase in the value of security holdings would cause lasting impacts on consumption growth and eventually consumption would increase by $1.03 \%$ : one-third of which increases during the first 9 months, another third of which occurs from the 10 th month to the 18 th month, another quarter of which occurs form the 19 th month to the 27 th month, and the rest occurs from the 28 th month to the 36 th month. This evidence can be largely captured by the RI model because (31) implies that the long-term consumption growth under RI is

$$
c_{t+1+S}-c_{t}=\theta\left[1+(1-\theta) / \phi+\cdots+((1-\theta) / \phi)^{S}\right] u_{t+1},
$$

which implies that $\lim _{S \rightarrow \infty}\left(c_{t+1+S}-c_{t}\right)=\frac{\theta u_{t+1}}{1-(1-\theta) / \phi}$. Consider a numerical example (the time unit here is 3 quarters) in which $\phi \simeq \beta=0.98$, when $\theta=40 \%$, that is, if on average the

\footnotetext{
${ }^{37}$ Kennickell, et. al (2000) and Starr-McCluer (2001) also reported similar results based on alternative survery sources.
} 
investors in the sample remove $40 \%$ of the uncertainty of the asset returns after observing the new signals about the returns, the long-term impact of the returns on consumption growth is $\lim _{S \rightarrow \infty}\left(c_{t+1+S}-c_{t}\right)=1.03$, which is exactly the same as that estimated from the data. When $S=0, c_{t+1+S}-c_{t}=\theta=40 \%$, as corresponds to the estimated $33 \%$; when $S=1, c_{t+1+S}-c_{t}=$ $\theta[1+(1-\theta) / \phi]=64 \%$, which is also close to the estimated impact $66 \%{ }^{38}$ Thus, our numerical example can generate results similar to those estimated from the US data. Furthermore, using the estimation results from Dynan and Maki (2001), we plot Figure 4 to illustrate the extent to which our RI model can match the survey results. In the left figure, we define stockholders (henceforth, "SH") as households with securities $>\$ 1,000$, whereas in the right figure, we define SH as households with securities $>\$ 10,000$. When we plot the profile generated from our model, we calibrate the observation weight $\theta$ such that the initial jump of consumption to the shock of asset returns can match the data exactly, and then check if the responses to past shocks during the following 27 quarters (3 time units) can also fit the dynamic responses reflected in the data. The left figure below shows that the RI model with $\kappa=0.2$ bits (that is, $\theta=24 \%$ ) can fit the empirical results quite well: the responses of consumption to the innovations is muted initially and then increases gradually over time. The right figure also shows a similar pattern of the responses, though the fit is not as good as the left one.

As in Gabaix and Laibson (2001), it is also interesting to examine whether the values of covar $\left[c_{t+1+S}-c_{t}, r_{t+1}^{e}\right]$ generated from the RI model can match the empirical counterparts. We use the cross-country panel dataset created by Campbell (1999) and plot the empirical covariances covar $\left[c_{t+1+S}-c_{t}, r_{t+1}^{e}\right]$ in US and the average covariance across countries with large stock markets in Figure $5 .{ }^{39}$ The figure shows a main feature in the data: the empirical covariances gradually increase with the horizon, $j$. Note that in the full information CCAPM model, the covariance should initially jump to a plateau and stay there. The figure also shows the covariance profiles generated by our RI model with different values of channel capacity. It is obvious that the RI model can capture this apparent empirical feature successfully: the covariance slowly rises over time. The intuition here is same as before: if a large number of consumers/investors in the economy can not digest the innovations to their financial wealth

\footnotetext{
${ }^{38}$ Note that in the data, one third of the impact increases during the first 9 months and another third of which occurs from the 10th month to the 18th month.

${ }^{39}$ Following the same criterion (ordered the countries in the dataset by the ratio of stock market capitalization to GDP) used in Gabaix and Laibson (2001), they are Switzerland (0.87), the United Kingdom (0.8), the United States (0.72), the Netherlands (0.46), Australia (0.42), and Japan (0.4).
} 
and monitor their wealth evolution due to limited information capacity constraints, aggregate consumption should react to the shock of asset returns with delay and be sensitive to lagged shocks.

\section{Conclusions}

Ordinary investors do not have infinite information-processing capacity; instead they only have finite capacity when processing available financial information. Rational inattention, first proposed by Sims (2003), has recently been introduced into economics and finance to model this type of information constraints. This paper takes such RI into account in an otherwise standard portfolio choice model and explores its effects on optimal consumption and portfolio rules and the equity premium in equilibrium.

The first contribution of this paper is that we explicitly solve an RI version of the intertemporal portfolio choice model and show that optimal consumption and portfolio rules under RI are interdependent. Second, we show that in the presence of RI, we need to use the ultimate consumption risk rather than the contemporaneous risk to measure the true riskiness of the risky asset because investors adjust their optimal plans slowly and incompletely. Holding the discount factor constant, the larger the degree of inattention, the greater the ultimate consumption risk. Consequently, RI reduces the demand for the risky asset. Hence, under RI, investment horizon does matter for long-term investment and RI could be an alternative explanation for significant non-stockownership. Finally, the explicit solution of consumption and asset holdings is in exact aggregation form. Aggregating across investors therefore depicts a joint dynamics of aggregate consumption and asset returns. We show that introducing RI could reconcile the following three observations in the US data simultaneously: (1) smooth aggregate consumption,

(2) the low contemporaneous correlation between aggregate consumption and asset returns, and (3) the implied high equity premium.

An interesting direction for future research is to model multiple risky assets in the RI model and examine whether RI can help resolve the "asset allocation puzzle". That is, the ratio of risky bonds to equities in the optimal portfolio increases with the coefficient of relative risk aversion, which is consistent with conventional portfolio advice but is inconsistent with static mean-variance analysis. It is also worthwhile examining how RI can be combined with the Epstein-Zin-Weil's recursive preference that also leads to a larger long-run risk and further 
improve the model's predictions on optimal investment and the joint behavior of aggregate consumption and the asset return.

\section{Appendix (Not for publication)}

\subsection{Solving the Standard Approximate Log-LQ model}

In the standard RE model, the approximate log-LQ model is

$$
\max _{c_{t}, \alpha} E_{0} \sum_{t=0}^{\infty} \beta^{t}\left[c_{t}+\frac{1}{2}(1-\gamma) c_{t}^{2}\right]
$$

subject to

$$
\Delta a_{t+1}=(1-1 / \phi)\left(c_{t}-a_{t}\right)+\psi+\left[\alpha\left(r_{t+1}^{e}-r^{f}\right)+r^{f}+\frac{1}{2} \alpha(1-\alpha) \omega^{2}\right] .
$$

We can first set up the Lagrangian function as follows

$$
L=E_{0} \sum_{t=0}^{\infty} \beta^{t}\left\{c_{t}+\frac{1}{2}(1-\gamma) c_{t}^{2}+\lambda_{t}\left(\begin{array}{c}
a_{t+1}-(1 / \phi) a_{t}-(1-1 / \phi) c_{t} \\
-\psi-\left[\alpha\left(r_{t+1}^{e}-r^{f}\right)+r^{f}+\frac{1}{2} \alpha(1-\alpha) \omega_{u}^{2}\right]
\end{array}\right)\right\}
$$

where $\lambda_{t}$ is the Lagrange multiplier, and the FOCs are:

$$
\begin{aligned}
& 1-(1-\gamma) c_{t}=(1-1 / \phi) \lambda_{t} \\
& \beta(1 / \phi) E_{t}\left[\lambda_{t+1}\right]=\lambda_{t} \\
& E_{t}\left[r_{t+1}^{e}-r^{f}+\frac{1}{2}(1-2 \alpha) \omega^{2}\right]=0
\end{aligned}
$$

which means that

$$
\begin{aligned}
c_{t} & =E_{t}\left[c_{t+1}\right], \\
\alpha & =\frac{\mu-r^{f}+0.5 \omega^{2}}{\omega^{2}}
\end{aligned}
$$

The lifetime budget constraint can be written as:

$$
(1 / \phi-1) \sum_{j=0}^{\infty} \phi^{j} c_{t+j}=(1 / \phi) a_{t}+\sum_{j=0}^{\infty} \phi^{j}\left[\alpha\left(r_{t+1+j}^{e}-r^{f}\right)+r^{f}+\frac{1}{2} \alpha(1-\alpha) \omega^{2}\right]+\psi /(1-\phi)
$$


Taking conditional expectations at time $t, E_{t}[\cdot]$, on both sides gives

$$
0=(1 / \phi) a_{t}-1 / \phi c_{t}+\left[\alpha\left(\mu-r^{f}\right)+r^{f}+\frac{1}{2} \alpha(1-\alpha) \omega^{2}\right] /(1-\phi)+\psi /(1-\phi) .
$$

substituting $c_{t}=E_{t}\left[c_{t+1}\right]$ into it gives the consumption function under RE:

$$
c_{t}=a_{t}+\log (1-\phi)
$$

which is the same as the consumption function (6) derived from the original nonlinear model when $\gamma \simeq 1$.

\subsection{Deriving the Expression of Consumption Growth, (20)}

Combining (5), (17), with (19) yields

$$
\widehat{a}_{t+1}-a_{t+1}=(1-\theta)(1 / \phi)\left(\widehat{a}_{t}-a_{t}\right)-(1-\theta) \alpha u_{t+1}+\theta \xi_{t+1},
$$

which implies that

$$
\widehat{a}_{t+1}-a_{t+1}=\frac{-(1-\theta) \alpha u_{t+1}+\theta \xi_{t+1}}{1-(1-\theta)(1 / \phi) \cdot L} .
$$

Furthermore, the change in the perceived state can be written as:

$$
\begin{aligned}
\Delta \widehat{a}_{t+1} & =\theta\left(a_{t+1}-\widehat{a}_{t}\right)+\theta \xi_{t+1} \\
& =\theta\left[\alpha u_{t+1}-(1 / \phi)\left(\widehat{a}_{t}-a_{t}\right)\right]+\theta \xi_{t+1} \\
& =\theta\left[\left(\frac{\alpha u_{t+1}}{1-(1-\theta)(1 / \phi) \cdot L}\right)+\left(\xi_{t+1}-\frac{\theta(1 / \phi) \xi_{t}}{1-(1-\theta)(1 / \phi) \cdot L}\right)\right] .
\end{aligned}
$$

\subsection{Deriving the Long-term Euler Equation, (21)}

When wealth is allocated efficiently across the two financial assets, the marginal investment in any asset yields the same expected increase in future utility:

$$
E_{t}\left[u^{\prime}\left(c_{t+1}\right)\left(R_{t+1}^{e}-R^{f}\right)\right]=0 .
$$


Using the Euler equation for the risk free asset between $t+1$ and $t+1+S$, we have

$$
u^{\prime}\left(c_{t+1}\right)=E_{t+1}\left[\left(\beta R_{f}\right)^{S} u^{\prime}\left(c_{t+1+S}\right)\right]
$$

which can be substituted into (42) to get the long-term Euler equation:

$$
\begin{aligned}
& E_{t}\left[E_{t+1}\left[\left(\beta R_{f}\right)^{S} u^{\prime}\left(c_{t+1+S}\right)\right]\left(R_{t+1}^{e}-R^{f}\right)\right] \\
= & E_{t}\left[E_{t+1}\left[\left(\beta R_{f}\right)^{S} u^{\prime}\left(c_{t+1+S}\right)\left(R_{t+1}^{e}-R^{f}\right)\right]\right] \\
= & E_{t}\left[\left(\beta R_{f}\right)^{S} u^{\prime}\left(c_{t+1+S}\right)\left(R_{t+1}^{e}-R^{f}\right)\right]=0,
\end{aligned}
$$

which implies

$$
E_{t}\left[u^{\prime}\left(c_{t+1+S}\right)\left(R_{t+1}^{e}-R^{f}\right)\right]=0,
$$

which can be transformed to Equation (21) in the text by dividing $u^{\prime}\left(c_{t}\right)$ on both sides. 


\section{References}

[1] Adam, Klaus (2005), "Optimal Monetary Policy in the Presence of Imperfect Common Knowledge," Journal of Monetary Economics 54 (2), 267-301.

[2] Ameriks, John and Stephen Zeldes (2004), "How Do Household Portfolio Shares Vary with Age?" Columbia University, mimeo.

[3] Bansal, Ravi, and Amil Yaron (2004), "Risks for the Long Run: A Potential Resolution of Asset Pricing Puzzles." Journal of Finance 59(4), 1481-1509.

[4] Campbell, John (1993), "Intertemporal Asset Pricing without Consumption Data," American Economic Review, vol. 83, 487-512.

[5] Campbell, John (2003), "Consumption-Based Asset Pricing," In George Constantinides, Milton Harris, and Rene Stultz, editors, Handbook of the Economics of Finance Volume 1B. Amsterdam: North-Holland, 803-887.

[6] Campbell, John and Luis M. Viceira (2002), "Strategic Asset Allocation: Portfolio Choice for Long-Term Investors," Oxford University Press, UK.

[7] Cochrane, John and Lars Peter Hansen (1992), "Asset Pricing Lessons for Macroeconomics," in 1992 NBER Macroeconomics Annual, Olivier Blanchard and Stanley Fischer (eds.), 115-1165.

[8] Cover, Thomas M. and Joy A. Thomas (1991), Elements of Information Theory, New York: John Wiley and Sons.

[9] Dynan, Karen and Maki, Dean (2001), "Does Stock Market Wealth Matter for Consumption?" Federal Reserve Board, mimeo.

[10] Gabaix, Xavier and David Laibson (2001), "The 6D bias and the Equity Premium Puzzle," NBER Macroeconomic Annual.

[11] Gennotte, Gerard (1986), "Optimal Portfolio Choice Under Incomplete Information," Journal of Finance 41, 733-746.

[12] Hansen, Lars and Kenneth Singleton (1983), "Stochastic Consumption, Risk Aversion, and the Temporal Behavior of Asset Returns," Journal of Political Economy 91, 249-265. 
[13] Hansen, Lars and Ravi Jagannathan (1991), "Implications of Security Market Data for Models of Dynamic Economies," Journal of Political Economy 99, 225-62.

[14] Hansen, Lars P., John C. Heaton and Nan Li, 2005. Consumption Strikes Back? Measuring Long-run Risk, University of Chicago, mimeo, .

[15] Huang, Lixing and Hong Liu (2006), "Rational Inattention and Portfolio Selection," Forthcoming Journal of Finance.

[16] Kennickell, A. B., M. Starr-McCluer, and B. Surette (2000), "Recent changes in U.S. family finances: Results from the 1998 Survey of Consumer Finances," Federal Reserve Bulletin, January 1-29.

[17] Kocherlakota, Narayana (1996), "The Equity Premium: It's Still a Puzzle," Journal of Economic Literature Vol. XXXIV, 42-71.

[18] Kocherlakota, Narayana and Ravi Jagannathan (1996), "Why Should Older People Invest Less in Stocks than Younger People?" Federal Reserve Bank of Minneapolis Quarterly Review.

[19] Luo, Yulei (2008), "Consumption Dynamics under Information Processing Constraints," Review of Economic Dynamics 11, 366-385.

[20] Luo, Yulei and Eric Young (2008), "Rational Inattention and Aggregate Fluctuations," manuscript, University of Hong Kong and University of Virginia.

[21] Lynch, Anthony (1996), "Decision Frequency and Synchronization across Agents: Implications for Aggregate Consumption and Equity Returns," Journal of Finance 51 (4), 14791497.

[22] Marshall, David and Nayan Parekh (1999), "Can Costs of Consumption Adjustment Explain Asset Prcing Puzzles," Journal of Finance 54(2) 623-654.

[23] Mehra, Rajnish and Prescott, Edward (1985), "The Equity Premium: A Puzzle," Journal of Monetary Economics 15, 145-161.

[24] Merton, Robert C., (1969), "Lifetime Portfolio Selection under Uncertainty: the Continuous Time Case," Review of Economics and Statistics 51, 247-257. 
[25] Moscarini, Giuspeppe (2004), "Limited Information Capacity as a Source of Inertia," Journal of Economic Control and Dynamics 2003-2035.

[26] Parker, Jonathan (2003), "Consumption Risk and Expected Stock Returns," NBER Working Paper 9548.

[27] Parker, Jonathan and Christian Julliard (2004), "Consumption Risk and the Cross-section of Expected Returns," Journal of Political Economy 113 (1), 185-222. .

[28] Peng, Lin (2004), "Learning with Information Capacity Constraints," Journal of Financial and Quantitative Analysis 40, 307-330.

[29] Peng, Lin and Wei Xiong (2006), "Investor Attention, Overconfidence and Category Learning," Journal of Financial Economics 80 (3), 563-602.

[30] Piazzesi, Monika (2002), "Comment" on Gabaix and Laibson, "The 6D Bias and the EquityPremium Puzzle". In NBER Macroeconomics Annual 2001, vol. 16.

[31] Shannon, Claude (1948), "A Mathematical Theory of Communication," The Bell System Technical Journal 27, 623-656.

[32] Sims, Christopher (2003), "Implications of Rational Inattention," Journal of Monetary Economics 50, 665-690.

[33] Sims, Christopher (2005), "Rational Inattention: A Research Agenda," Princeton University, mimeo.

[34] Starr-McCluer, Martha (2000), "Stock Market Wealth and Consumption," Federal Reserve Board, mimeo.

[35] Van Nieuwerburgh, Stijn and Veldkamp, Laura (2006), "Information Acquisition and Portfolio Under-Diversification," New York University, mimeo.

[36] Viceira, Luis (2001), "Optimal Portfolio Choice for Long-Horizon Investors with Nontradable Labor Income," The Journal of Finance 56 (2), 433-470.

[37] Vissing-Jørgensen, Annette (2002), "Limited Asset Market Participation and Elasticity of Intertemporal Substitution," Journal of Political Economy 110(4), 825-853. 
[38] Weil, Philippe (1989), "The Equity Premium Puzzle and the Risk-Free Rate Puzzle," Journal of Monetary Economics 24, 401-421. 


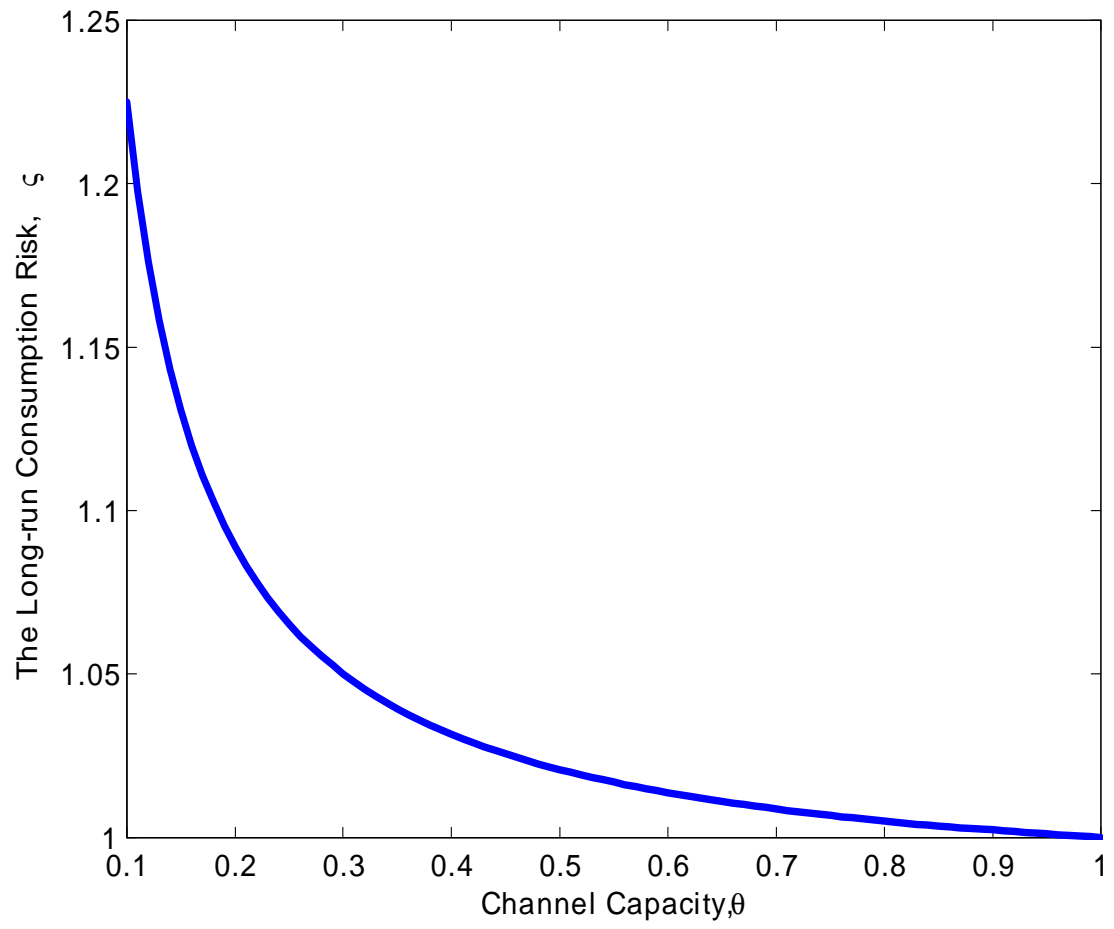

Figure 1: The relationship between $\theta$ and $\varsigma$.

Note: Here we set the discount factor $\beta=0.98$ quarterly. 


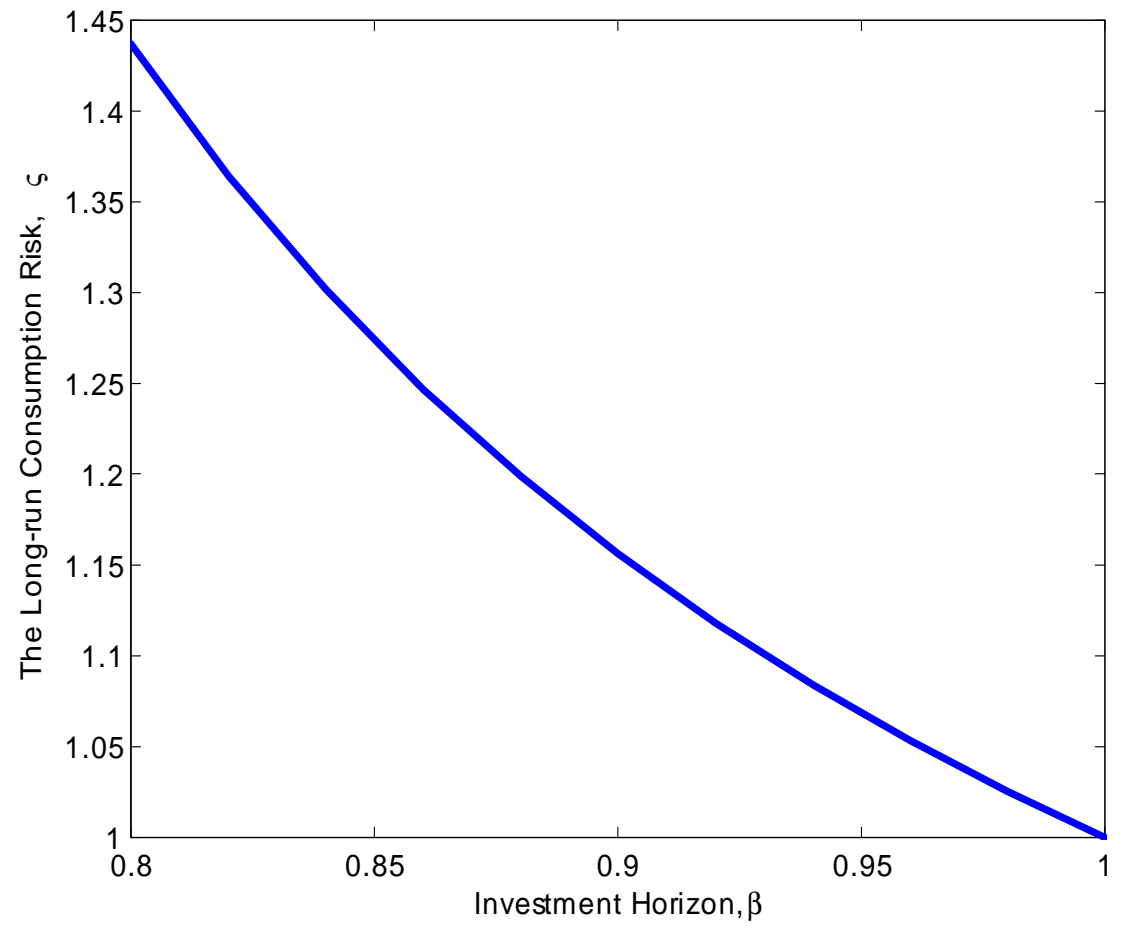

Figure 2: The relationship between $\beta$ and $\varsigma$.

Note: Here we set the degree of inattention $\kappa=0.26$ bits, that is, $\theta=30 \%$. 


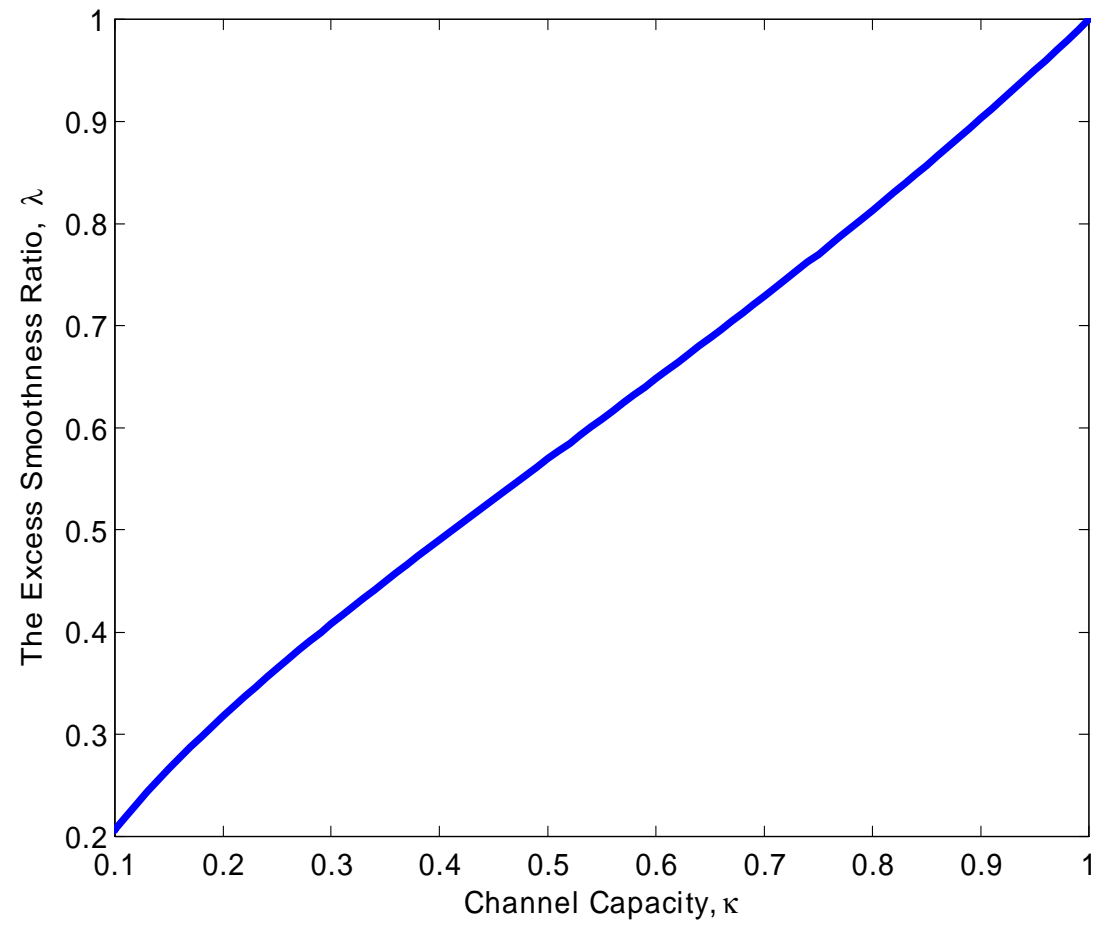

Figure 3: The Excess Smoothness Ratio of Aggregate Consumption.

Note: Here we set the time discount factor $\beta=0.985$ quarterly. The unit of $\kappa$ is "bit". 


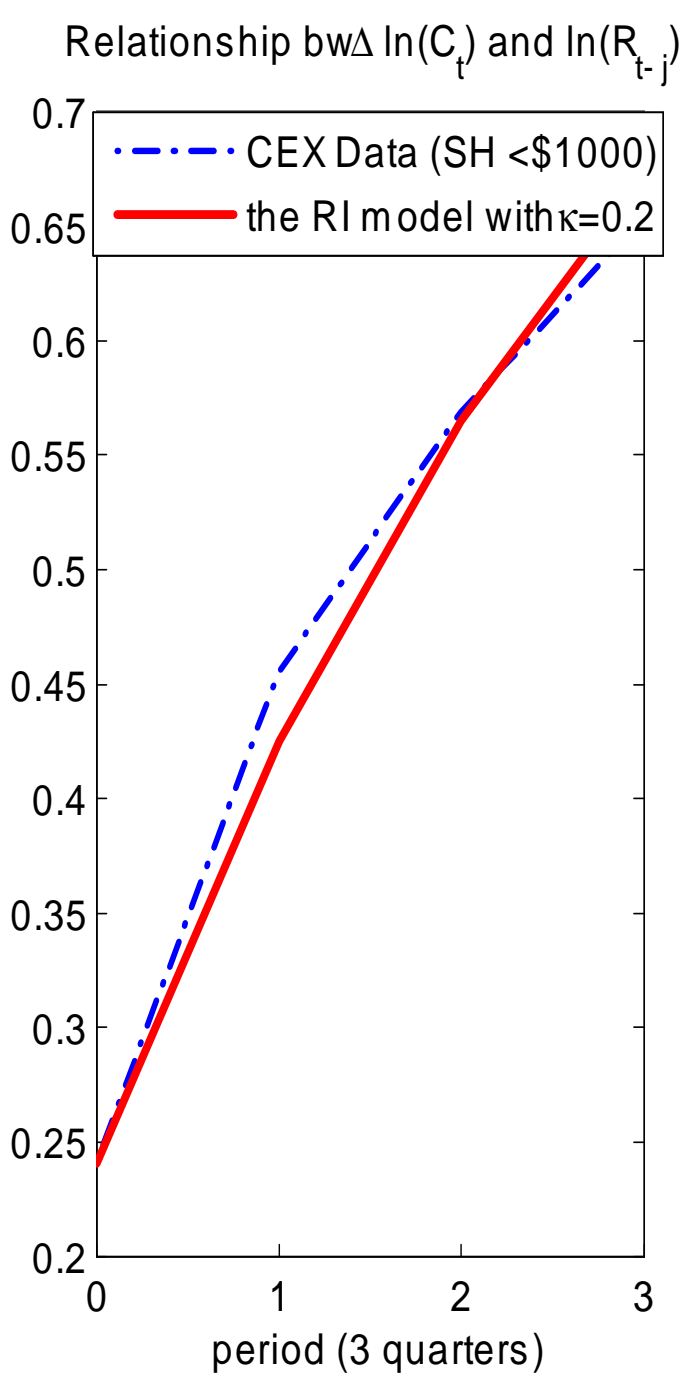

Relationship bw $\Delta \ln \left(\mathrm{C}_{\mathrm{t}}\right)$ and $\ln \left(\mathrm{R}_{\mathrm{t}-\mathrm{j}}\right)$

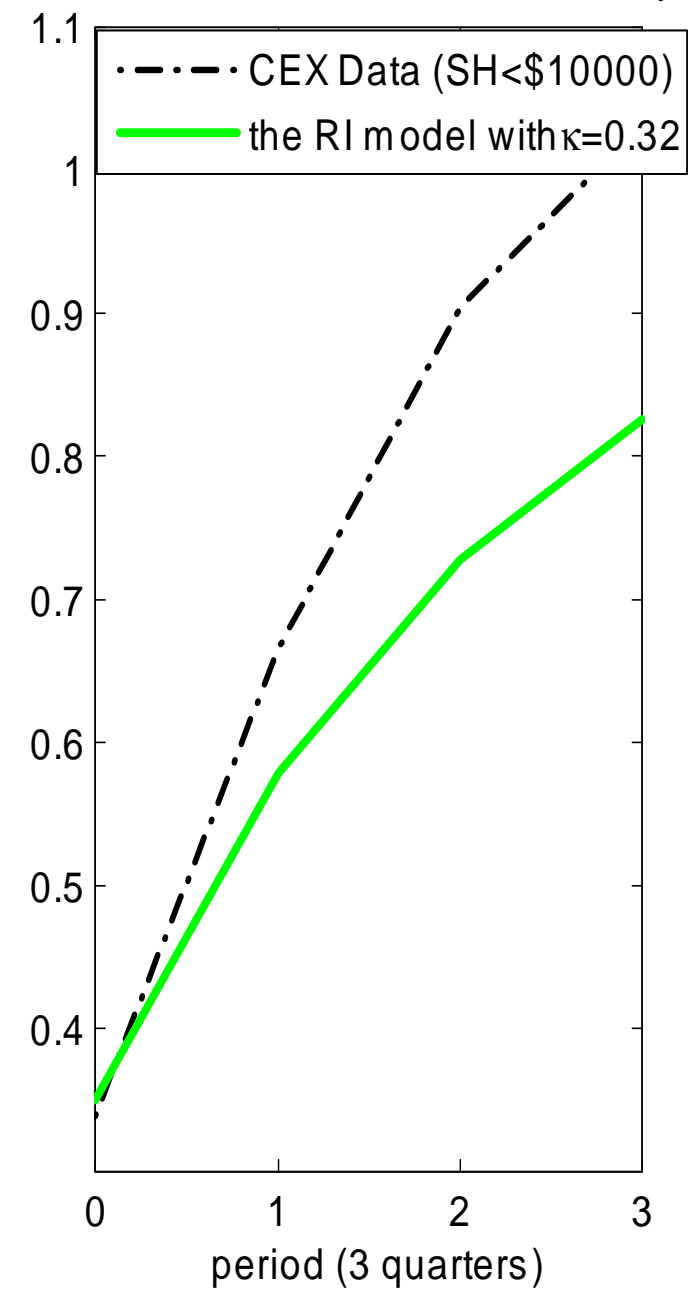

Figure 4: The long-run impacts of the return on stockholders' consumption

Note: when we compute the model's predictions, $\beta$ is set to 0.98 quarterly. The unit of $\kappa$ is "bit", so that $\kappa=0.2$ and 0.32 bits correspond to $\theta=24 \%$ and $36 \%$, respectively. 


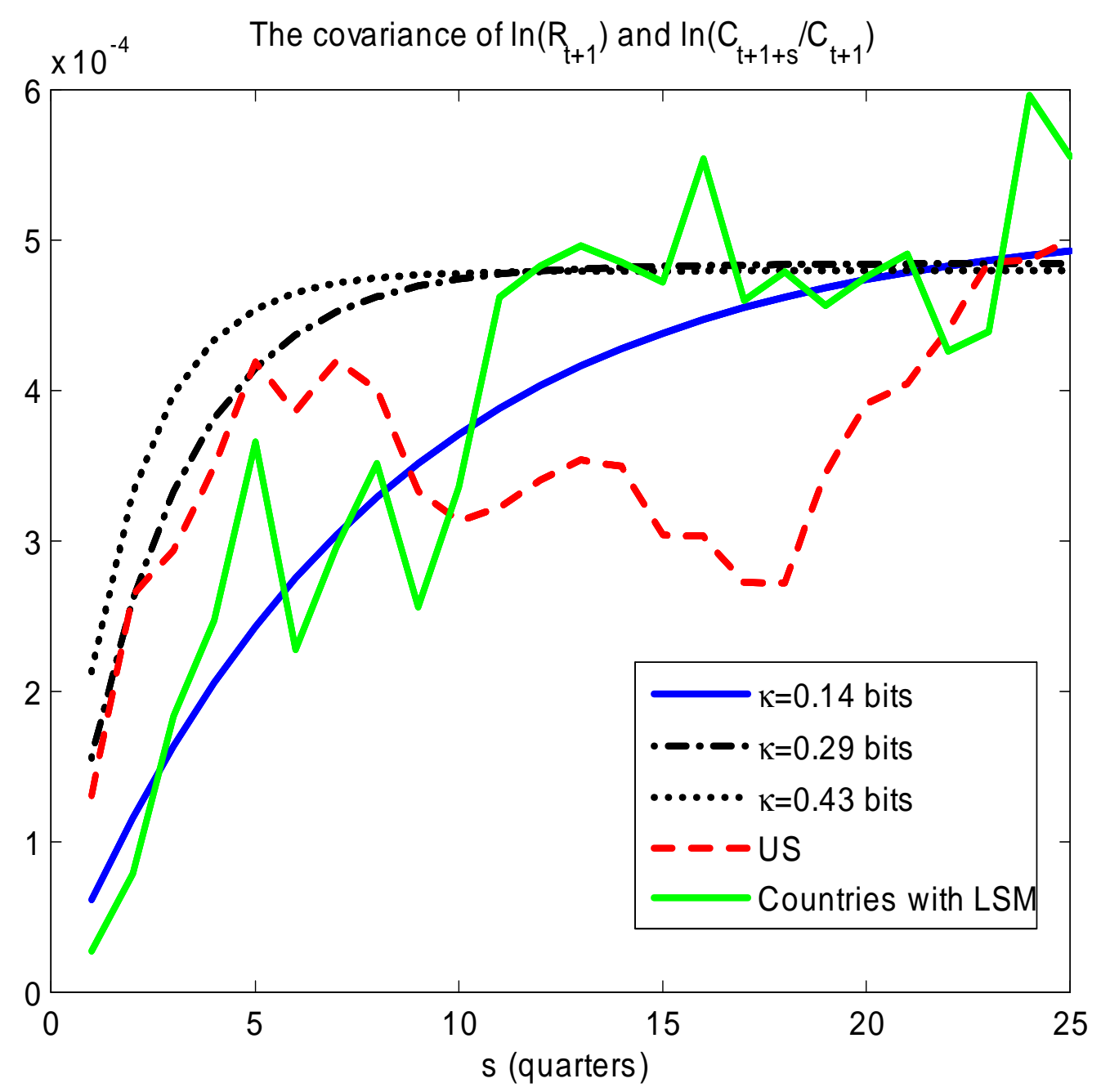

Figure 5: The covariances between the equity return and consumption growth.

Note: when we compute the theoretical covariances, the time discount factor $\beta$ is set to 0.98 quarterly and $\gamma=1.001$. The capacity $\kappa=0.14,0.29$, and 0.43 bits correspond to $\theta=18 \%, 33 \%$, and $45 \%$, respectively. "LSM" in the figure means "large stock markets". 